\title{
The association between serum 25 -hydroxyvitamin $D$ level and recurrent falls in the elderly population: a cohort study
}

\author{
Hamed Basir Ghafouri ${ }^{1}$, Morteza Zare ${ }^{2}$, Azam Bazrafshan ${ }^{3}$, Ehsan Modirian ${ }^{4}$, Afkham Mousavi ${ }^{5}$, Niloofar \\ Abazarian $^{6}$
}

${ }^{1}$ MD, Assistant Professor of Emergency Medicine, Emergency Medicine Management Research Center, Iran University of Medical Sciences, Tehran, Iran

${ }^{2}$ MS, Nutrition Research Center, School of Nutrition and Food Sciences, Shiraz University of Medical Sciences, Shiraz, Iran

${ }^{3}$ MS, Neuroscience Research Center, Institute of Neuropharmacology, Kerman University of Medical Sciences, Kerman, Iran

${ }^{4}$ MD, MPH, Emergency Medicine Physician, Boali Hospital, Quazvin University of Medical Science, Quazvin, Iran

${ }^{5}$ MD, Department of Emergency Medicine, Shohada-e- Hafe Tir Hospital, Iran University of Medical Sciences, Tehran, Iran

${ }^{6} \mathrm{MD}$, Trauma and Injury Research Center, Iran University of Medical Sciences, Tehran, Iran

\section{Type of article: Original}

\begin{abstract}
Introduction: Serum vitamin D concentration is a major contributing factor for increasing the risk of fall and fall-related injuries in older adults. However, when prescribed and supplemented for these populations, the outcomes are controversial, and in several cases no improvement has been reported in reducing the risk of recurrent falls. This study aimed to examine the association between serum vitamin D concentration and recurrent falls in Iranian older adults.

Methods: This cohort study was conducted in the emergency departments of two university hospitals. A cohort of 82 elderly participants aged over 60 and suffered from an unintentional episode of falling was evaluated six months after their first ED visit. A structured, self-administered checklist was developed to obtain the participants' demographic and clinical information. Participants also were asked about any recurrent fall experience during follow-up.

Results: The mean (SD) age of the study population was 75 (8). Over half of the participants were male (57.3\%). The mean (median) serum 25-hydroxyvitamin D (25 (OH)D) concentration was $38(34) \mathrm{ng} / \mathrm{ml}$. Mean serum $25(\mathrm{OH}) \mathrm{D}$ levels varied slightly between gender groups $(\mathrm{p}=0.450)$. An inverse but insignificant association was found between the age of participants and their serum 25(OH)D levels $(r=-0.03, p=0.7)$. A small but insignificant association also was found between the mean serum 25(OH)D level and the number of recurrent falls in elderly patients irrespective of their age, gender, or physical activity groups $(\mathrm{OR}=1.008, \mathrm{p}=0.992)$.

Conclusion: In contrast to previous studies, no significant association of serum $25(\mathrm{OH}) \mathrm{D}$ concentration was found with recurrent falls in Iranian older adults.

Keywords: 25-hydroxyvitamin D,falls, Vitamin D insufficiency, Iran, Elderly

\section{Introduction}

Falls are the leading cause of injury and deaths among older adults worldwide with an estimated 424,000 cases reported each year (1). Over $30 \%$ of those aged over 65 or older and $40-50 \%$ of those over 80 currently are treated for fall-related injuries (2). Recurrent falls among older adults have a significant financial, social, psychological, and health-related burden on society, particularly on the health care system. Since falls and fall-related injuries result in the loss of over 17 million disability-adjusted life years (DALYs), they are considered to be a major public health
\end{abstract}

\section{Corresponding author:}

Dr. Niloofar Abazarian, Trauma and Injury Research Center, Iran University of Medical Sciences, Tehran, Iran. Tel: +98.9374609619 Fax:+98.3432263857, Email: abzarian.niloofar@gmail.com Received: November 11, 2015, Accepted: March 02, 2016, Published: August 2016 iThenticate screening: March 02, 2016, English editing: May 19, 2016, Quality control: July 04, 2016

(c) 2016 The Authors. This is an open access article under the terms of the Creative Commons Attribution-NonCommercialNoDerivs License, which permits use and distribution in any medium, provided the original work is properly cited, the use is non-commercial and no modifications or adaptations are made. 
challenge across the world that calls for global action. In this context, the rapidly increasing number of older adults and the associated risk of fall-related injuries underlines ongoing concerns about the quality of life, costs of care, and demands for support services and preventive programs for vulnerable populations. Serum Vitamin D insufficiency has been implemented as a major risk factor for osteoporosis, muscle weakness $(3)$, falls $(2,4)$, fractures $(5,6)$ and even mortality $(7-9)$. The association between vitamin D insufficiency and the risk of fracture and injuries has been estimated in several studies $(5,6,10,11)$. Most of the studies have investigated the effect of serum 25-hydroxyvitamin D $(25(\mathrm{OH}) \mathrm{D})$ concentration, which is the best indicator of vitamin D status, on bone mineral density (BMD) changes $(6,12,13)$. Therefore, it has been suggested that vitamin $\mathrm{D}$ is a major determinant of bone health. It also has been indicated that low 25(OH)D levelshave been associated with low BMD in older white adults $(12,14)$. In this regard, further investigations indicated a positive association between serum 25(OH)D and BMD of the hip $(5,6,11)$ and spine in men. Some other studies have suggested that vitamin D has a protective effect on fractures by improving muscle functions and reduced risk of falling $(2-4,8)$. In these studies, low 25(OH)D was found to be associated with poor grip strength, an indicator of muscle strength, balance, and increased risk of mortality in elderly patients. Despite its well-documented protective effects, serum 25(OH)D concentration is likely to be one of the most globally-considered contributing factors to BMD changes, muscle strength, fractures, and falls. Serum 25(OH)D supplementation has been prescribed repeatedly as a preventive drug for older people, yet there are surprising small number of well-documented randomized, controlled trials measuring its efficacy and potential to reduce the risk of fractures and falls (15). Prescription of vitamin D supplementation for older people is based on clinical experience rather than well documented, randomized trials that involve an extensive population with different outcomes (15). While a great body of the literature suggests vitamin D supplementation as the major contributing factors for reducing the risk of falls and fractures in elderly people, it is unclear whether its efficacy and potential performance leads to better results. Therefore, further efforts are needed to investigate the effect of serum 25(OH)D concentration on the risk of falls in older populations. Recent data have failed to find any protective effect of $25(\mathrm{OH}) \mathrm{D}$ on the risk or rates of falling in older people, yet the association between $25(\mathrm{OH}) \mathrm{D}$ concentration level and the risk of falling in older adults has been a topic of heavy debate among healthcare professionals, and, therefore, more investigations are needed to provide evidence of how $25(\mathrm{OH}) \mathrm{D}$ status is associated with the risk of recurrent falls. In an attempt to address these challenges, the present study aimed to conduct a preliminary investigation of the association between serum $25(\mathrm{OH}) \mathrm{D}$ levels and the risk of recurrent falls in the elderly Iranian population.

\section{Material and Methods \\ 2.1. Study Setting and Participants}

This cohort study was conducted in the emergency departments (EDs) of Rasoul Akram and Sina Hospitals during March 2012- January 2013. A cohort of elderly participants over 60 who suffered from an unintentional episode of falling was evaluated six months after of their first ED visit. Of all 120 patients invited to participate in the study, 82 ultimately remained to the end of the study. Exclusion criteria were the use of vitamin D supplements, anti-seizure medications, or glucocorticoids.

\subsection{Data collection and Follow-up}

A structured, self-administered checklist was developed to obtain the participants' demographic and clinical information. The questionnaire included demographic information (age, gender, level of education, marital status), past medical history, and serum 25(OH)D concentration of included participants at the time of hospitalization. This checklist was completed during admission and in a six-month of follow up through telephone calls to the patients, their family, or caregivers who were aware of the patients' conditions. We also asked about any recurrent fall experience during the six-month follow-up. Those who reported recurrent falls were asked about the frequency of their falls.

\subsection{5(OH)D Analysis and Statistical analysis}

A valid serum $25(\mathrm{OH}) \mathrm{D}$ sample was obtained from all of the patients who participated in the study. Non-fasting blood samples were collected from participants during their first visit to the clinic. The serum concentration of 25(OH)D was measured by separating the serum from $5 \mathrm{~cm} 3$ of clotted blood taken from the participants. All samples were stored at $-20 \mathrm{oC}$ and then transferred to the Reference Laboratory. The serum $25(\mathrm{OH}) \mathrm{D}$ concentration was measured using the Enzyme-Linked Immunosorbent Assay (ELISA) method. Data analysis was performed using Stata version 12 (Stata Corp., College Station, TX). Descriptive statistics (mean, median, SD and range) were used to present the overall characteristics of the participants. Spearman's regression coefficient was used to measure 
the associations between the quantitative variables. In order to compare the mean serum 25(OH)D concentration between different categorical variables, the Mann-Whitney U and Kruskal-Wallis tests were used.

\subsection{Ethics Approval and Informed Consent}

All participants gave written informed consent. Ethical approval was granted by the Iran University of Medical Sciences' Research Ethics Committee.

\section{Results}

\subsection{Characteristics of Participants}

The mean (SD) age of the study population was 75 (8). Over half of the participants were male (57.3\%), and about $80 \%$ lived in private homes. Table 1 presents the participants' characteristics according to the three levels of serum 25(OH)D studied.

Table 1. Descriptive Characteristics of Participants, Aged 60 and Older Living in the Community According to Serum 25(OH)D Level

\begin{tabular}{|c|c|c|c|c|c|c|}
\hline Variables & Characteristics & $\mathrm{n}(\%)$ & $\begin{array}{l}25(\mathrm{OH}) \mathrm{D} ; \text { Mean } \\
\text { (median) }\end{array}$ & $\begin{array}{l}<30 \mathrm{ng} / \mathrm{ml} \\
(\%)\end{array}$ & $\begin{array}{l}30-100 \mathrm{ng} / \mathrm{ml} \\
(\%)\end{array}$ & $\begin{array}{l}100-150 \\
\mathrm{ng} / \mathrm{ml}(\%)\end{array}$ \\
\hline \multirow[t]{2}{*}{ Gender } & Male & $47(57.3)$ & $39.1(36)$ & $16(45.7)$ & $30(66.7)$ & $1(50)$ \\
\hline & Female & $35(42.7)$ & $36.8(28)$ & $19(54.3)$ & $15(33.3)$ & $1(50)$ \\
\hline \multirow[t]{3}{*}{ Marital state } & Married & $52(63.4)$ & $38.5(36)$ & $21(60)$ & $30(66.7)$ & $1(50)$ \\
\hline & Widow & $26(31.7)$ & $37.3(39)$ & $13(37.1)$ & $12(26.7)$ & $1(50)$ \\
\hline & Single & $4(4.9)$ & $37.7(40.5)$ & $1(2.9)$ & $3(6.7)$ & $0(0)$ \\
\hline \multirow[t]{2}{*}{ Residence } & Private home & $65(79.3)$ & $37.06(34)$ & $28(80)$ & $36(80)$ & $1(50)$ \\
\hline & Children's home & $17(20.7)$ & $42.2(34)$ & $7(20)$ & $9(20)$ & $1(50)$ \\
\hline \multirow[t]{4}{*}{ Age (year) } & $60-70$ & $29(35.4)$ & $36.3(33)$ & $14(40)$ & $14(31.1)$ & $1(50)$ \\
\hline & $71-80$ & $34(41.5)$ & $43.4(37)$ & $14(40)$ & $19(42.2)$ & $1(50)$ \\
\hline & $81-90$ & $16(19.5)$ & $34.2(34.5)$ & $4(11.4)$ & $12(26.7)$ & $0(0)$ \\
\hline & $>90$ & $3(3.7)$ & $15.3(10)$ & $3(8.6)$ & $0(0)$ & $0(0)$ \\
\hline \multirow{5}{*}{$\begin{array}{l}\text { Past medical } \\
\text { history }\end{array}$} & $\mathrm{DM}$ & $16(19.5)$ & $41.3(30)$ & $8(22.9)$ & $7(15.6)$ & $1(50)$ \\
\hline & HTN & $23(28.1)$ & $36.5(36)$ & $8(22.9)$ & $14(31.1)$ & $1(50)$ \\
\hline & HLP & $13(15.8)$ & $34(36)$ & $5(14.3)$ & $8(17.8)$ & 0 \\
\hline & CAD & $18(21.9)$ & $39.1(29)$ & $10(28.6)$ & $8(17.8)$ & 0 \\
\hline & CVA & $12(14.6)$ & $39.8(36.5)$ & $4(11.4)$ & $8(17.8)$ & 0 \\
\hline \multirow{4}{*}{$\begin{array}{l}\text { BMI } \\
\left(\mathrm{kg} / \mathrm{M}^{2}\right)\end{array}$} & $<20$ & $8(9.8)$ & $42.7(29)$ & $4(11.4)$ & $3(6.7)$ & $1(50)$ \\
\hline & $20-24.9$ & $38(46.3)$ & $37.7(36)$ & $14(40)$ & $23(51.1)$ & $1(50)$ \\
\hline & $25-29.9$ & $31(37.8)$ & $38(33)$ & $15(42.9)$ & $16(35.6)$ & $0(0)$ \\
\hline & $>30$ & $5(6.1)$ & $33.6(31)$ & $2(5.7)$ & $3(6.7)$ & $0(0)$ \\
\hline \multirow{2}{*}{$\begin{array}{l}\text { Physical } \\
\text { activity }\end{array}$} & $<80$ & $75(91.5)$ & $36.2(32)$ & & $39(86.7)$ & $1(50)$ \\
\hline & $>80$ & $7(8.5)$ & $58.8(42)$ & & $6(13.3)$ & $1(50)$ \\
\hline \multirow{2}{*}{$\begin{array}{l}\text { Muscle } \\
\text { weakness }\end{array}$} & Yes & $6(7.3)$ & $34.1(32)$ & $2(5.7)$ & $4(8.9)$ & $0(0)$ \\
\hline & No & $76(92.7)$ & $38.4(34.5)$ & $33(94.3)$ & $41(91.1)$ & $2(100)$ \\
\hline \multirow{2}{*}{$\begin{array}{l}\text { Dynamic } \\
\text { balance }\end{array}$} & Good & $39(47.6)$ & $36.7(36)$ & $16(45.7)$ & $23(51.1)$ & $0(0)$ \\
\hline & $\begin{array}{l}\text { Poor, not } \\
\text { completed }\end{array}$ & $43(52.4)$ & $39.3(33)$ & $19(54.3)$ & $22(48.9)$ & $2(100)$ \\
\hline
\end{tabular}

\subsection{Distribution of Serum 25(OH)D Concentration}

The mean (median) serum 25(OH)D concentration was $38(34) \mathrm{ng} / \mathrm{ml}$. Mean serum 25(OH)D levels varied little according to gender groups, men had higher levels of $25(\mathrm{OH}) \mathrm{D}$ rather than women (39.1 vs. 36.8, respectively, $\mathrm{p}=0.450)$. In addition, mean serum 25(OH)D levels differed between the age groups, ranging from $15.3 \mathrm{ng} / \mathrm{ml}$ in those aged over 90 to $43.4 \mathrm{ng} / \mathrm{ml}$ in those aged 71-80. According to this finding, an inverse, but insignificant, association was found between the age of participants and their serum 25(OH)D levels $(r=-0.03, p=0.7)$. Table 1 indicates that the mean serum 25(OH)D levels decreased according to BMI categories (from 42.7 to $33.6 \mathrm{ng} / \mathrm{ml}$, $\mathrm{P}=0.986)$. Mean serum 25(OH)D level was significantly higher in the group with physical activity of more than 80 min per week $(\mathrm{P}=0.03)$. However, the mean serum $25(\mathrm{OH}) \mathrm{D}$ level was found to have no significant association with muscle weakness $(\mathrm{p}=0.979)$ or dynamic balance $\operatorname{scores}(\mathrm{p}=0.90)$. 


\subsection{The Effect of Serum 25(OH)D Concentration on Falls}

Figure 1 indicates the distribution of serum $25(\mathrm{OH}) \mathrm{D}$ according to recurrent falls and gender categories. According to this figure, the median serum $25(\mathrm{OH}) \mathrm{D}$ concentration was higher in men than in women. Besides, the median serum $25(\mathrm{OH}) \mathrm{D}$ concentration was decreased insignificantly in line with the increasing number of recurrent falls. However, in women, the median of the serum $25(\mathrm{OH}) \mathrm{D}$ concentration followed a different pattern, in which women who experienced recurrent falls had higher scores of serum $25(\mathrm{OH})$ than others $(\mathrm{p}=0.643)$. According to these findings, a small but insignificant association was found between the mean serum $25(\mathrm{OH}) \mathrm{D}$ level and the number of recurrent falls in elderly patients irrespective of their age, gender, or physical activity groups $(\mathrm{OR}=1.008, \mathrm{p}=0.992)$.

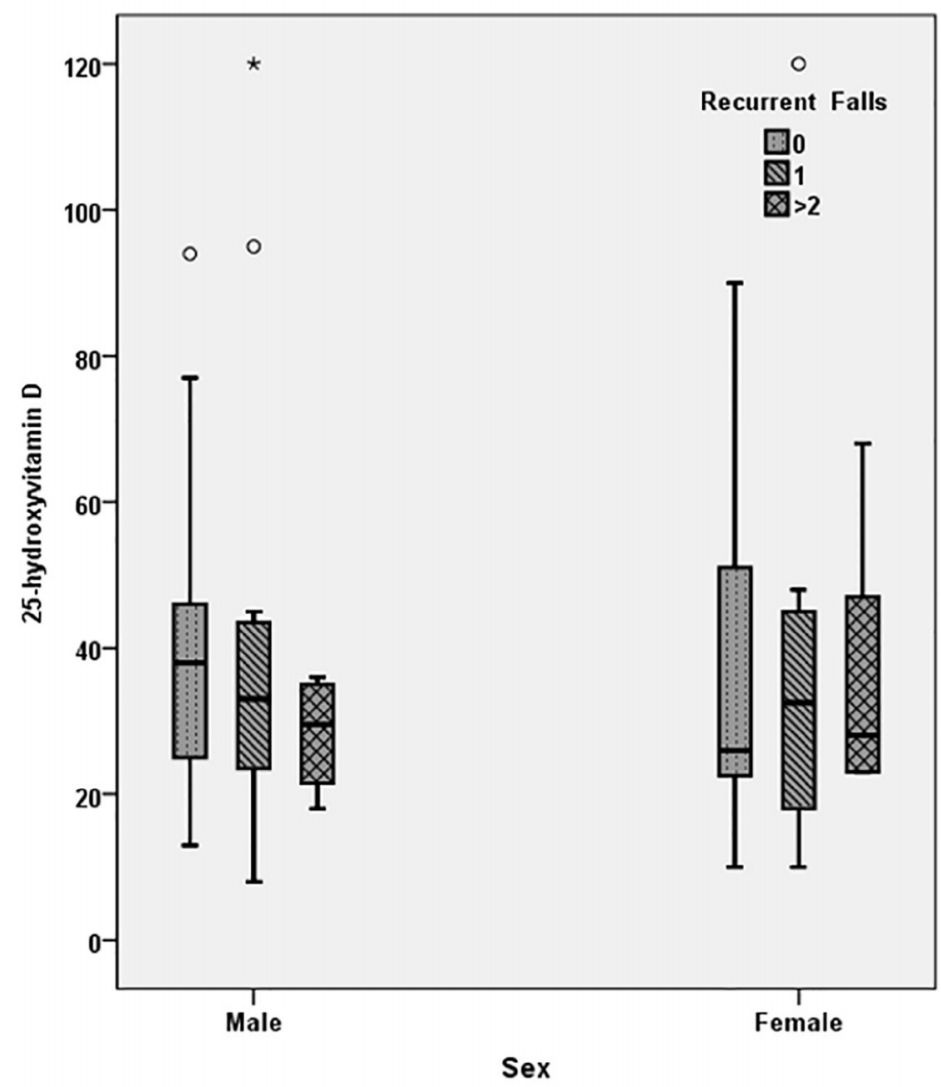

Figure 1. Distribution of Serum 25(OH)D according to recurrent falls and gender categories in participants aged 60 and older in the community

\section{Discussion}

In this prospective cohort study of elderly people that were treated in emergency rooms for injuries from falls, no significant association was observed between their serum $25(\mathrm{OH}) \mathrm{D}$ concentration and recurrent falls. In addition, mean serum $25(\mathrm{OH}) \mathrm{D}$ concentration was not associated with muscle weakness and balance in older adults. In this study, no significant association of $25(\mathrm{OH}) \mathrm{D}$ was found with incidence of one or more recurrent falls. In contrast to previous reports, our findings did not support the argument that vitamin D concentration reduces the risk of recurrent falls in elderly people. Similar to our findings, in a survey by Faulkner et al., the relationship between serum concentration of vitamin D metabolites and falls in older women in the United States was examined, and it was reported that the risk of falling only decreased with high serum $1,25(\mathrm{OH})_{2} \mathrm{D}_{3}$ concentration, whereas higher $25(\mathrm{OH}) \mathrm{D}$ level was not associated with lower risk (16). Serum $1,25(\mathrm{OH})_{2} \mathrm{D}_{3}$ concentration was not assessed in participants in our study because of laboratory limitations, but our findings confirmed the second result of this study in that is showed that there was no association between $25(\mathrm{OH}) \mathrm{D}$ levels and falls. In a meta-analysis of randomized controlled trials, the efficacy of the administration of vitamin D and calcium supplements in elderly people to reduce the frequency of falls was examined, but the results found no efficacy (10). The findings of previous studies have suggested that low vitamin D status is associated with increased risk of falling and fractures. Therefore, vitamin D supplementation has been implemented as a strategy in increasing BMD and reducing the risk of fractures or falls in 
older people. Vitamin D concentration has been suggested repeatedly to be the contributing factor for BMD changes, falls, fractures, and physical performance in older people, but emerging evidence highlights ongoing debates on the protective effect of vitamin D concentration on falls and fractures. While prescribing vitamin $D$ for preventing unfavorable outcomes of bone resorption and turnover is based on clinical practice and cohort studies, there is now evidence that failed to identify any protective effect of vitamin D supplementation on the risk or rate of falling in older people (both in healthcare facilities or hospitals and in the community) $(15,17,18)$. Our findings also indicated no significant association of $25(\mathrm{OH}) \mathrm{D}$ concentration and muscle weakness in older adults. This result was consistent with the findings of a systematic review and meta-analysis that examined the effect of vitamin D concentration on muscle strength in adults (19). According to this evidence, vitamin D supplementation showed no significant effect on grip strength, knee flexion strength, or knee extension strength in adults with baseline 25(OH)D $>25 \mathrm{nmol} / \mathrm{L}$. These results provided further evidence that the function, metabolism, and absorption of vitamin D may differ among individuals and even across diverse populations (15). However, limited early investigations have suggested an increase in proximal muscle strength in adults with vitamin D deficiency (3). In this context, universal recommendations on the use of vitamin D supplementation to improve muscle strength and physical performance of older adults' require further evidence. Our study was limited in several aspects. First, the design of our study did not allow us to investigate the causality effect of vitamin D and recurrent falls. Also, we did not consider important covariates, including body mass index, education, smoking, use of alcohol, and health status when we analyzed the potential associations between serum vitamin $\mathrm{D}$ concentration and recurrent falls in older people. In addition, a single baseline measurement of serum vitamin $\mathrm{D}$, was used to categorize the participants, and this could have led to misclassification of the participants, because single baseline measurements may not have reflected their long-term biochemical status. We excluded those subjects who took vitamin D supplements during the six-month follow-up. The efficacy of vitamin D supplements in reducing recurrent falls was not investigated in our study. Despite these limitations, this study has several unique strengths. First, this is the first population-based study to examine the incidence of recurrent fractures with serum vitamin D concentration in the Iranian population. Therefore, these findings provide further evidence of the effect of vitamin D on recurrent falls in people with diverse ethnic backgrounds. Second, this study used direct serum measures of vitamin D instead of other indirect measures, including questionnaire-based scales or food frequency intakes of vitamin D-rich foods. In summary, our study findings failed to support the argument that vitamin D concentration is associated with the reduced risk of falling in older adults. No significant association of vitamin D was found with incidence of recurrent falls, muscle activity, and balance.

\section{Conclusions}

The association between vitamin D insufficiency and the risk of fracture and injuries has been investigated repeatedly, but the results remain controversial across different populations. Therefore, this study aimed to investigate the protective role of vitamin D concentration against falls in the elderly Iranian population. By using serum vitamin $\mathrm{D}$ concentration as a direct measure of vitamin $\mathrm{D}$, this study failed to support the argument that vitamin $\mathrm{D}$ concentration is associated with the reduced risk of falling in older adults. According to our findings, no significant association was observed between serum vitamin D concentration and recurrent falls, muscle activity, and balance. Our findings provided further evidence that the function, metabolism, and absorption of vitamin D may differ among individuals and even across diverse populations. Yet, the results are still incomplete, and further trials are needed to reach conclusive decisions.

\section{Acknowledgments:}

This work supported in part by the Iran University of Medical Sciences with research grant number 18050. The authors thank the staff of the Deputy for Research at the Iran University of Medical Sciences for their financial support.

\section{Conflict of Interest:}

There is no conflict of interest to be declared.

Authors' contributions:

All authors contributed to this project and article equally. All authors read and approved the final manuscript.

\section{References:}

1) World Health organization, Falls. 2012, World Health Organization.

2) Bischoff-Ferrari HA, Dawson-Hughes B, Willett WC, Staehelin HB, Bazemore MG, Zee RY, et al. Effect of vitamin D on falls: a meta-analysis. JAMA. 2004; 291(16): 1999-2006. doi: 10.1001/jama.291.16.1999, PMID: 15113819. 
3) Barker T, Henriksen VT, Martins TB, Hill HR, Kjeldsberg CR, Schneider ED, et al. Higher serum 25hydroxyvitamin D concentrations associate with a faster recovery of skeletal muscle strength after muscular injury. Nutrients. 2013; 5(4): 1253-75. doi: 10.3390/nu5041253.

4) Murad MH, Elamin KB, Abu Elnour NO, Elamin MB, Alkatib AA, Fatourechi MM, et al. Clinical review: The effect of vitamin D on falls: a systematic review and meta-analysis. J Clin Endocrinol Metab . 2011; 96(10): 2997-3006. doi: 10.1210/jc.2011-1193, PMID: 21795448.

5) Holvik K, Ahmed LA, Forsmo S, Gjesdal CG, Grimnes G, Samuelsen SO, et al. Low serum levels of 25hydroxyvitamin D predict hip fracture in the elderly: a NOREPOS study. J Clin Endocrinol Metab. 2013; 98(8): 3341-50. doi: 10.1210/jc.2013-1468, PMID: 23678033.

6) Steingrimsdottir L, Halldorsson T, Siggeirsdottir K, Cotch MF, Einarsdottir BO, Eiriksdottir G, et al. Hip fractures and bone mineral density in the elderly--importance of serum 25-hydroxyvitamin D. PloS One. 2014; 9(3). doi: 10.1371/journal.pone.0091122, PMID: 24621578, PMCID: PMC3951316.

7) Durup D, Jørgensen HL, Christensen J, Schwarz P, Heegaard AM, Lind B. A reverse J-shaped association of all-cause mortality with serum 25 -hydroxyvitamin $\mathrm{D}$ in general practice: the CopD study. J Clin Endocrinol Metab. 2012; 97(8): 1-9. doi: 10.1210/jc.2012-1176, PMID: 22573406.

8) Hirani V, Cumming RG, Naganathan V, Blyth F, Le Couteur DG, Handelsman DJ, et al. Associations Between Serum 25-Hydroxyvitamin D Concentrations and Multiple Health Conditions, Physical Performance Measures, Disability, and All Cause Mortality: The Concord Health and Ageing in Men Project. J Am Geriatr Soc. 2014; 62(3): 417-25. doi: 10.1111/jgs.12693, PMID: 24576190.

9) Chowdhury R, Kunutsor S, Vitezova A, Oliver-Williams C, Chowdhury S, Kiefte-de-Jong JC, et al. Vitamin D and risk of cause specific death: systematic review and meta-analysis of observational cohort and randomised intervention studies. BMJ. 2014; 348(g1903): 2-13. doi: 10.1136/bmj.g1903.

10) Jackson $R D$, LaCroix AZ, Gass M, Wallace RB, Robbins J, Lewis CE, et al. Calcium plus vitamin $D$ supplementation and the risk of fractures. $N$ Engl J Med. 2006; 354(7): 669-83. doi: 10.1056/NEJMoa055218, PMID: 16481635.

11) Wang Xg, Yang B, Wang Yh, Cui Ly, Luo Jp. Serum Levels of 25-hydroxyvitamin D and Functional Outcome in Older Patients with Hip Fracture. J Arthroplasty. 2015; 30(5): 891-4. doi: 10.1016/j.arth.2014.12.018, PMID: 25603761.

12) Hannan MT, Litman HJ, Araujo AB, McLennan CE, McLean RR, McKinlay JB, et al. Serum 25hydroxyvitamin $\mathrm{D}$ and bone mineral density in a racially and ethnically diverse group of men. J Clin Endocrinol Metab. 2013; 93(1): 40-6. doi: 10.1210/jc.2007-1217, PMID: 17986641, PMCID: PMC2190744.

13) Hwang YC, Ahn HY, Jeong IK, Ahn KJ, Chung HY. Optimal serum concentration of 25 -hydroxyvitamin D for bone health in older Korean adults. Calcif Tissue Int. 2013; 92(1): 68-74. doi: 10.1007/s00223-0129669-3, PMID: 23179104.

14) Lips P, Duong TU, Oleksik A, Black D, Cummings S, Cox D, et al. A global study of vitamin D status and parathyroid function in postmenopausal women with osteoporosis: baseline data from the multiple outcomes of raloxifene evaluation clinical trial. J Clin Endocrinol Metab. 2001; 86(3): 1212-21. doi: 10.1210/jcem.86.3.7327, PMID: 11238511.

15) Theodoratou E, Tzoulaki I, Zgaga L, Ioannidis JPA. Vitamin D and multiple health outcomes: umbrella review of systematic reviews and meta-analyses of observational studies and randomised trials. BMJ. 2014; 348(g2035): 2-19. doi: 10.1136/bmj.g2035.

16) Faulkner KA, Cauley JA, Zmuda JM, Landsittel DP, Newman AB, Studenski SA, et al. Higher 1, 25dihydroxyvitamin $\mathrm{D} 3$ concentrations associated with lower fall rates in older community-dwelling women. Osteoporos Int. 2006; 17(9): 1318-28. PMID: 16788853.

17) Cameron ID, Gillespie LD, Robertson MC, Murray GR, Hill KD, Cumming RG, et al. Interventions for preventing falls in older people in care facilities and hospitals. Cochrane Database Syst Rev. 2012; 12. doi:10.1002/14651858.CD005465.pub3, PMID: 23235623.

18) Gillespie LD, Robertson MC, Gillespie WJ, Lamb SE, Gates S, Cumming RG, et al. Interventions for preventing falls in older people living in the community. Cochrane Database Syst Rev. 2009; 2(CD007146). doi: 10.1002/14651858.CD007146.pub2, PMID: 19370674.

19) Stockton KA, Mengersen K, Paratz JD, Kandiah D, Bennell KL. Effect of vitamin D supplementation on muscle strength: a systematic review and meta-analysis. Osteoporos Int. 2011; 22(3): 859-71. doi: 10.1007/s00198-010-1407-y, PMID: 20924748. 